\title{
Tindak Tutur
}

\section{OLEH}

\author{
Harziko
}

\begin{abstract}
Abstrack
Tindak tutur adalah bagian dari pragmatik. Tindak tutur merupakan pengujaran kalimat untuk menyatakan agar suatu maksud dari pembicara diketahui pendengaran. Tindak tutur (speech atcs) adalah ujaran yang dibuat sebagai bagian dari interaksi social. Menurut Leoni (dalam Sumarsono, dan Paina Partama, 2010:329-330) tindak tutur merupakan bagian dari peristiwa tutur, dan peristiwa tutur merupakan bagian dari situasi tutur. Setiap peristiwa tutur terbatas pada kegiatan, atau aspek-aspek kegiatan yang secara langsung diatur oleh kaidah atau norma bagi penutur. Dengan demikian, tindakan merupakan karakteristik tuturan dalam komunikasi. Diasumsikan bahwa dalam merealisasikan tuturan atau wacana, seseorang berbuat sesuatu, yaitu performansi tindakan. Tuturan yang berupa performansi tindakan ini disebut dengan tuturan performatif, yakni tuturan yang dimaksudkan untuk melakukan suatu tindakan.
\end{abstract}

Kata Kunci. Tindak Tututr, Pragmatik 


\section{PENDAHULUAN}

Tindak tutur merupakan gejala individu, bersifat psikologis, dan ditentukan oleh kemampuan bahasa penutur dalam menghadapi situasi tertentu. Tindak tutur dititikberatkan kepada makna atau arti tindak, sedangkan peristiwa tutur lebih dititikberatkan pada tujuan peristiwanya. Dalam tindak tutur ini terjadi peristiwa tutur yang dilakukan penutur kepada mitra tutur dalam rangka menyampaikan komunikasi. Austin (dalam Subyakto, 1992:33) menekanka tindak tutur dari segi pembicara. Kalimat yang bentuk formalnya berupa10 pertanyaan memberikan informasi dan dapat pula berfungsi melakukan suatu tindak tutur yang dilakukan oleh penutur. Dari uraian di atas dapat disimpulkan bahwa tindak tutur adalah kegiatanseseorang menggunakan bahasa kepada mitra tutur dalam rangka mengkomunikasikan sesuatu

Apa makna yang dikomukasikan tidak hanya dapat dipahami berdasarkan penggunaan bahasa dalam bertutur tersebut tetapi juga ditentukan oleh aspek-aspek komunikasi secara komprehensif, termasuk aspekaspek situasional komunikasi. Guru dan siswa merupakan komponen dalam pengajaran holistik. Antara guru dengan siswa saling berpengaruh dan saling mendorong untuk melakukan kegiatan yang satu dengan kegiatan yang lain. Pada dasarnya, siswa adalah unsur penentu dalam pembelajaran holistic.

Austin (1962:94-107) membagi tindak tutur menjadi tiga macam tindakan, yaitu tindakan menginformasikan atau menyatakan sesuatu "The act of saying something", yang disebut dengan tindak lokusi, tindakan menghendaki mitra tuturnya untuk melakukan sesuatu, "The act of doing something" atau tindak ilokusi, dan tindakan memberikan pengaruh terhadap mitra tutur atau menghendaki adanya reaksi atau efek atau hasil tertentu dari mitra tutur, "The act of affecting someone" atau tindak perlokusi. 


\section{Daftar Pustaka}

Sam, B., Iye, R., Ohoibor, M., Umanailo, M. C. B., Rusdi, M., Rahman, A. B. D., \& Hajar, I. (2019). Female Feminism in the Customary Island of Buru. Int. J. Sci. Technol. Res, 8(8), 1877-1880.

Susiati, S. (2018). Homonim bahasa kepulauan tukang besi dialek kaledupa di kabupaten wakatobi [the homonymon of tukang besi island languange in kaledupa dialect at wakatobi regency]. Totobuang, 6 (1), 109, 123.

Iye, R., \& Susiati, S. (2018). NILAI EDUKATIF DALAM NOVEL SEBAIT CINTA DI BAWAH LANGIT KAIRO KARYA MAHMUD JAUHARI ALI (Educative Values in Sebait Cinta di Bawah Langit Kairo by Mahmud Jauhari Ali). Sirok Bastra, 6(2), 185-191.

Susiati, S., Iye, R., \& Suherman, L. O. A. (2019). Hot Potatoes Multimedia Applications in Evaluation of Indonesian Learning In SMP Students in Buru District. ELS Journal on Interdisciplinary Studies in Humanities, 2(4), 556-570.

Susiati, S., \& Iye, R. (2018). Kajian Geografi Bahasa dan Dialek di Sulawesi Tenggara: Analisis Dialektometri. Gramatika: Jurnal Ilmiah Kebahasaan dan Kesastraan, 6(2), 137-151.

Iye, R., Susiati, S., \& Karim, K. (2020). Citra Perempuan dalam Iklan Sabun Shinzui. Sang Pencerah: Jurnal Ilmiah Universitas Muhammadiyah Buton, 6(1), 1-7.1

Lafamane, F. (2020). Perkembangan Teori Sastra (suatu Pengantar).

Susiati, S. (2020). GAYA BAHASA SECARA UMUM DAN GAYA BAHASA PEMBUNGKUS PIKIRAN.

Iye, R. (2018). Tuturan emosi mahasiswa kota baubau dalam ranah demonstrasi.

Iye, R., Tenriawali, A. Y., Susiati, A., \& Buton, D. (2020). Makna dan Fungsi Emosi Mahasiswa Kota Baubau dalam Ranah Demonstrasi: The Meaning And Emotional Function Of Students Of Baubau City In The Demonstration Plan. Uniqbu Journal of Social Sciences, 1(1), 25-37.

Lafamane, F. (2020). Perkembangan Teori Sastra (suatu Pengantar).

Lafamane, F. (2020). Perkembangan Teori Sastra (suatu Pengantar).

Buru, K. M. S. PENGARUH MOTIVASI BELAJAR DI SMA NEGERI 2 BURU.

Yusnan, M., Kamasiah, R. I., Karim, H., \& Bugis, R. (2020). Alih Kode dan Campur Kode pada Novel Badai Matahari Andalusia Karya Hary El-parsia: Transfer Code And Mix Code In Novels Badai Matahari Andalusia Karya Hary El-parsia. Uniqbu Journal of Social Sciences, 1(1), 1-12.

YANTI, K. NILAI-NILAI MORAL DALAM TOKOH UTAMA PADA NOVEL SATIN MERAH. 
Susiati, S. (2020). Konsep Pertentangan Dalam Film" Aisyah Biarkan Kami Bersaudara" Karya Herwin Novianto.

Susiati, S. (2020). Gaya Bahasa Secara Umum Dan Gaya Bahasa Pembungkus Pikiran: Stilistika.

Iye, R., Tenriawali, A. Y., Susiati, A., \& Buton, D. (2020). Makna dan Fungsi Emosi Mahasiswa Kota Baubau dalam Ranah Demonstrasi: The Meaning And Emotional Function Of Students Of Baubau City In The Demonstration Plan. Uniqbu Journal of Social Sciences, 1(1), 25-37.

Iye, R. WRITING SKILLS IN SMP USWATUN HASANAH. BURU DISTRICT.

iye, r. (2020, March 10). DEIKSIS MASYARAKAT BONEGUNU KABUPATEN BUTON UTARA. https://doi.org/10.31228/osf.io/seqan. 10.31228/osf.io/seqan

Iye, R. (2018). Tuturan dalam Prosesi Lamaran Pernikahan di Tomia Kabupaten Wakatobi. Jurnal Totobuang, 6(2).

Susiati, S. (2020). PENTINGNYA MELESTARIKAN BAHASA DAERAH.

Umanailo, M. C. B. Cia-Cia Vocational Inventoryization In Buru District.

BURU, U. I. MODEL KOOPERATIF LEARNING TIPE STAD DALAM MENINGKATKAN KEMAMPUAN MENGAPRESIASI CERITA FIKSI DI SD NEGERI 1 NAMLEA.

Iye, R. H. NILAI-NILAI MORAL DALAM TOKOH UTAMA PADA NOVEL SATIN MERAH KARYA BRAHMANTO ANINDITO DAN RIE YANTI. TELAGA BAHASA,(7), 2, 195-206.

Lafamane, F. (2020). Perkembangan Teori Sastra (suatu Pengantar).

Iye, R. Jl Prof Dr HAR Basalamah No, and Namlea-Kab Buru.". TUTURAN DALAM PROSESI LAMARAN PERNIKAHAN DI TOMIA KABUPATEN WAKATOBI." Kontemporer. Bandung: PT Remaja.

Harziko, H., Said, I. M., \& Darwis, K. (2018). FOLLOW THE EVENTS IN THE INDONESIAN LANGUAGE EXPRESSIVE SAID TRANSACTION IN THE TRADITIONAL MARKET TOWN OF BAUBAU. JURNAL ILMU BUDAYA, 6(1).

sofie, samsudiin, Iye, R., Tenriawali, A. Y., \& Susiati, S. (2021). IDEOLOGI PRANGGAPAN PAMFLET SOSIALISASI PELESTARIAN LINGKUNGAN DI KABUPATEN BURU. BAHTERA : Jurnal Pendidikan Bahasa Dan Sastra, 20(1), 72-83. https://doi.org/10.21009/bahtera.201.07.

Nurlatu, J., Bugis, R. K., Karim, K., Azwan, A., \& Iye, R. (2020). Penggunaan Dieksis Sopan Santun Mahasiswa Universitas Iqra Buru. Jurnal Ilmiah FONEMA: Jurnal Edukasi Bahasa dan Sastra Indonesia, 3(2), 154-164.

BURU, U. I. MODEL KOOPERATIF LEARNING TIPE STAD DALAM MENINGKATKAN KEMAMPUAN MENGAPRESIASI CERITA FIKSI DI SD NEGERI 1 NAMLEA. 
No, J. S. Q., Baruga, K. K., \& Bassalama, J. P. A. PRAANGGAPAN PAMFLET SOSIALISASI PELESTARIAN LINGKUNGAN DI KABUPATEN WAKATOBI.

Karim, A. B., \& Yusnan, M. (2020). Aspek Spiritual Dalam Novel Tuhan Izinkan Aku Menjadi Pelacur Karya Muhidin M Dahlan: Spiritual Aspects in the Lovely of God Let Me Become a Property of Muhidin M Dahlan. Uniqbu Journal of Social Sciences, 1(1), 61-71.

Sam, B., Iye, R., Ohoibor, M., Umanailo, M. C. B., Rusdi, M., Rahman, A. B. D., \& Hajar, I. Female Feminism in the Customary Island of Buru.

Susiati, S. PERWUJUDAN SIMILE OLEH MERARI SIREGAR DALAM NOVEL AZAB DAN SENGSARA.

Iye, R. (2018). Tuturan emosi mahasiswa kota baubau dalam ranah demonstrasi.

SENGSARA, D. PERWUJUDAN SIMILE OLEH MERARI SIREGAR DALAM NOVEL AZAB DAN SENGSARA EMBODIMENT OF SIMILE BY MERARI SIREGAR IN NOVEL AZAB.

Sam, B., Iye, R., Ohoibor, M., Umanailo, M. C. B., Rusdi, M., Rahman, A. B. D., \& Hajar, I. Female Feminism in the Customary Island of Buru.

Andini, K. NILAI BUDAYA SUKU BAJO SAMPELA DALAM FILM THE MIRROR NEVER LIES KARYA KAMILA ANDINI.

Susiati, S., Iye, R., \& Suherman, L. O. A. (2019). Hot Potatoes Multimedia Applications in Evaluation of Indonesian Learning In SMP Students in Buru District. ELS Journal on Interdisciplinary Studies in Humanities, 2(4), 556-570.

Andini, K. NILAI BUDAYA SUKU BAJO SAMPELA DALAM FILM THE MIRROR NEVER LIES KARYA KAMILA ANDINI.

Iye, R., Susiati, S., \& Karim, K. (2020). Citra Perempuan dalam Iklan Sabun Shinzui. Sang Pencerah: Jurnal Ilmiah Universitas Muhammadiyah Buton, 6(1), 1-7.

Susiati, S. (2018). Homonim bahasa kepulauan tukang besi dialek kaledupa di kabupaten wakatobi [the homonymon of tukang besi island languange in kaledupa dialect at wakatobi regency]. Totobuang, 6 (1), 109, 123.

Susiati, S., \& Iye, R. (2018). Kajian Geografi Bahasa dan Dialek di Sulawesi Tenggara: Analisis Dialektometri. Gramatika: Jurnal Ilmiah Kebahasaan dan Kesastraan, 6(2), 137-151.

Harziko, H., Said, I. M., \& Darwis, K. (2018). FOLLOW THE EVENTS IN THE INDONESIAN LANGUAGE EXPRESSIVE SAID TRANSACTION IN THE TRADITIONAL MARKET TOWN OF BAUBAU. JURNAL ILMU BUDAYA, 6(1).

Susiati, S., \& Iye, R. (2018). Kajian Geografi Bahasa dan Dialek di Sulawesi Tenggara: Analisis Dialektometri. Gramatika: Jurnal Ilmiah Kebahasaan dan Kesastraan. 6 (2), 137-151. 
Iye, R. Jl Prof Dr HAR Basalamah No, and Namlea-Kab Buru.". TUTURAN DALAM PROSESI LAMARAN PERNIKAHAN DI TOMIA KABUPATEN WAKATOBI." Kontemporer. Bandung: PT Remaja.

Susiati, S. (2020). Pengaplikasian Multimedia Hot Potatoes Dalam Evaluasi Pembelajaran Bahasa Indonesia Pada Siswa SMP Negeri 9 Buru.

Iye, R. H. NILAI-NILAI MORAL DALAM TOKOH UTAMA PADA NOVEL SATIN MERAH KARYA BRAHMANTO ANINDITO DAN RIE YANTI. TELAGA BAHASA,(7), 2, 195-206.

BURU, I. PENGEMBANGAN APLIKASI MULTIMEDIA HOT POTATOES DALAM EVALUASI PEMBELAJARAN BAHASA INDONESIA PADA SISWA SMP NEGERI 9 BURU (DEVELOPMENT OF HOT POTATOES MULTIMEDIA APPLICATIONS IN EVALUATION OF INDONESIAN LEARNING IN SMP 9 STUDENTS.

Umanailo, M. C. B. Cia-Cia Vocational Inventoryization In Buru District.

Susiati, S. (2020). Wujud Morfologi Bahasa Indonesia.

No, J. S. Q., Baruga, K. K., \& Bassalama, J. P. A. PRAANGGAPAN PAMFLET SOSIALISASI PELESTARIAN LINGKUNGAN DI KABUPATEN WAKATOBI.

YANTI, K. NILAI-NILAI MORAL DALAM TOKOH UTAMA PADA NOVEL SATIN MERAH.

PSP2M, T., \& Iye, R. TUTURAN EMOSI MAHASISWA KOTA BAU BAU.

No, J. S. Q., Baruga, K. K., \& Bassalama, J. P. A. PRAANGGAPAN PAMFLET SOSIALISASI PELESTARIAN LINGKUNGAN DI KABUPATEN WAKATOBI.

YANTI, K. B. A. D. R. NILAI-NILAI MORAL DALAM TOKOH UTAMA PADA NOVEL SATIN MERAH.

PSP2M, T., \& Iye, R. TUTURAN EMOSI MAHASISWA KOTA BAU BAU.

Umanailo, M. C. B. Cia-Cia Vocational Inventoryization In Buru District.

Umanailo, M. Chairul Basrun. "Cia-Cia Vocational Inventoryization In Buru District."

Susiati, Y. T. Risman Iye. A. Kesantunan Imperatif Bahasa Indonesia Suku Bajo Sampela: Balai Pembinaan dan Pengembangan Bahasa. 2018. Kongres Bahasa Indonesia (No. 12, pp. 1-6). Report.

Nacikit, J. PENTINGNYA MELESTARIKAN BAHASA DAERAH.

BURU, I. PENGEMBANGAN APLIKASI MULTIMEDIA HOT POTATOES DALAM EVALUASI PEMBELAJARAN BAHASA INDONESIA PADA SISWA SMP NEGERI 9 BURU (DEVELOPMENT OF HOT POTATOES MULTIMEDIA APPLICATIONS IN EVALUATION OF INDONESIAN LEARNING IN SMP 9 STUDENTS.

Susiati, S. (2020). PENTINGNYA MELESTARIKAN BAHASA DAERAH. 
Iye, R. (2018). Tuturan dalam Prosesi Lamaran Pernikahan di Tomia Kabupaten Wakatobi. Jurnal Totobuang, 6(2).

Iye, R., Susiati, S., \& Karim, K. (2020). Citra Perempuan dalam Iklan Sabun Shinzui. Sang Pencerah: Jurnal Ilmiah Universitas Muhammadiyah Buton, 6(1), 1-7.

Umanailo, M. C. B. Cia-Cia Vocational Inventoryization In Buru District.

Iye, R., \& Susiati, S. (2018). NILAI EDUKATIF DALAM NOVEL SEBAIT CINTA DI BAWAH LANGIT KAIRO KARYA MAHMUD JAUHARI ALI (Educative Values in Sebait Cinta di Bawah Langit Kairo by Mahmud Jauhari Ali). Sirok Bastra, 6(2), 185-191.

Umanailo, M. C. B. Cia-Cia Vocational Inventoryization In Buru District.

BURU, U. I. MODEL KOOPERATIF LEARNING TIPE STAD DALAM MENINGKATKAN KEMAMPUAN MENGAPRESIASI CERITA FIKSI DI SD NEGERI 1 NAMLEA.

Buru, K. M. S. PENGARUH MOTIVASI BELAJAR DI SMA NEGERI 2 BURU.

BURU, U. I. MODEL KOOPERATIF LEARNING TIPE STAD DALAM MENINGKATKAN KEMAMPUAN MENGAPRESIASI CERITA FIKSI DI SD NEGERI 1 NAMLEA.

Buru, K. M. S. PENGARUH MOTIVASI BELAJAR DI SMA NEGERI 2 BURU.

Sam, Belinda, Risman Iye, Mirja Ohoibor, M. Chairul Basrun Umanailo, M. Rusdi, A. B. D. Rahman, and Ibnu Hajar. "Female Feminism in the Customary Island of Buru."

Sam, Belinda, Risman Iye, Mirja Ohoibor, M. Chairul Basrun Umanailo, M. Rusdi, A. B. D. Rahman, and Ibnu Hajar. "Female Feminism in the Customary Island of Buru.".

Widyawaty, E. D., \& Andriani, R. (2018). Hubungan Pengetahuan Ibu Hamil Trimester II-III Tentang Senam Hamil Dengan Melakukan Senam Hamil. NERSMID: Jurnal Keperawatan dan Kebidanan, 1(2), 119-140.

Widyawaty, E. D. (2018). HUBUNGAN BREASTFEEDING DENGAN INVOLUSI UTERUS PADA IBU NIFAS 0-7 HARI DI WILAYAH KERJA PUSKESMAS TANJUNGANOM KABUPATEN NGANJUK TAHUN 2017. EMBRIO, 10(1), 20-25.

Widyawaty, E. D. (2018). HUBUNGAN BREASTFEEDING DENGAN INVOLUSI UTERUS PADA IBU NIFAS 0-7 HARI DI WILAYAH KERJA PUSKESMAS TANJUNGANOM KABUPATEN NGANJUK TAHUN 2017. EMBRIO, 10(1), 20-25.

Yuniati, E. (2021). Enterprise Innovation In Service Independent Practice Of Midwives In Indonesia: Literature Review. Turkish Journal of Computer and Mathematics Education (TURCOMAT), 12(7), 1834-1840.

Setiawandari, S., \& Widyawaty, E. D. (2021). Efektivitas Ekstrak Bawang Merah (Allium ascalonicum L) Terhadap Penurunan Suhu Tubuh Anak dengan Demam 
Pasca Imunisasi DPT Pentabio. 2-TRIK: TUNAS-TUNAS RISET KESEHATAN, 11(1), 6-11.

Nugraha, A. P. H. S., Widyawaty, E. D., Hernanto, F. F., Indrianita, V., \& Kristianto, H. (2020). EFFECT OF NUTMEG AND LAVENDER ESSENTIAL OIL ON BLOOD PRESSURE IN THE ELDERLY WITH HYPERTENSION. PalArch's Journal of Archaeology of Egypt/Egyptology, 17(6), 10076-10083.

Nugraha, A. S. P. H. H. (2020). Pengaruh Essensial Oil dari Biji Pala dan Lavender terhadap Tekanan Darah pada Lansia dengan Hipertensi. NERSMID: Jurnal Keperawatan dan Kebidanan, 3(2), 76-84.

Widyawaty, E. D., \& Fajrin, D. H. (2020). Pengaruh Daun Lembayung (Vigna sinensis L.) Terhadap Peningkatan Produksi Asi Pada Ibu Menyusui Bayi 0-6 Bulan. NERSMID: Jurnal Keperawatan dan Kebidanan, 3(2), 93-100.

Widyawaty, E. D. (2020). STUDI KUANTITATIF TENTANG HUBUNGAN MINAT IBU HAMIL DALAM MENGKONSUMSI TABLET FE DENGAN KEJADIAN ANEMIA. Health Care Media, 4(1), 32-36.I

Widyawaty, E. D. (2019). Hubungan Riwayat Status Gizi Ibu Saat Hamil Dengan Berat Badan Lahir. NersMid, 2(1).I

Dewi, F. P., Hidayat, A., ST, S., \& Keb, M. (2011). FAKTOR PREDISPOSISI DIARE PADA BALITA DI POLIKLINIK DAN PONDOK BERSALIN NURUL HUDA KABUPATEN MAGELANG DESEMBER 2010-JANUARI 2011 (Doctoral dissertation, Universitas' Aisyiyah Yogyakarta).

Abriani, A. A., Ningtyias, F. W., \& Sulistiyani, S. Hubungan Antara Konsumsi Makan, Status Gizi, dan Aktivitas Fisik dengan Kejadian Pre Menstrual Syndrome (The Relationship between Food Consumption, Nutritional Status, and Physical Activity with Pre Menstrual Syndrome).

WIDYAWATY, E. D. (2018). PENGARUH PEMBERIAN EKSTRAK MENIRAN (Phyllanthus niruri L.) TERHADAP EKSPRESI IGF-1 DAN KETEBALAN ENDOMETRIUM PADA MENCIT (Mus musculus) BETINA MODEL ENDOMETRIOSIS (Doctoral dissertation, Fakultas Kedokteran).

Martalisa, A. A., \& Widyawaty, E. D. (2018). Hubungan Motivasi Keluarga Ibu Hamil dengan Keteraturan Mengkonsumsi Tablet Fe. NERSMID: Jurnal Keperawatan dan Kebidanan, 1(2), 156-171.

EKA DEVIANY WIDYAWATY, N. (2018). PENGARUH PEMBERIAN EKSTRAK MENIRAN (Phyllanthus niruri L.) TERHADAP EKSPRESI IGF-1 DAN KETEBALAN ENDOMETRIUM PADA MENCIT (Mus musculus) BETINA MODEL ENDOMETRIOSIS (Doctoral dissertation, Fakultas Kedokteran).

WIDYAWATY, E. D. (2018). PENGARUH PEMBERIAN EKSTRAK MENIRAN (Phyllanthus niruri L.) TERHADAP EKSPRESI IGF-1 DAN KETEBALAN ENDOMETRIUM PADA MENCIT (Mus musculus) BETINA MODEL ENDOMETRIOSIS (Doctoral dissertation, Fakultas Kedokteran). 
Widyawaty, E. D. (2018). Pengaruh Meniran Dosis Bertingkat Terhadap Ekspresi IGF-1 Dan Ketebalan Endometrium Pada Mencit Betina Model Endometriosis. Jurnal Biosains Pascasarjana, 20(1), 9-21.

EKA DEVIANY WIDYAWATY, N. (2018). PENGARUH PEMBERIAN EKSTRAK MENIRAN (Phyllanthus niruri L.) TERHADAP EKSPRESI IGF-1 DAN KETEBALAN ENDOMETRIUM PADA MENCIT (Mus musculus) BETINA MODEL ENDOMETRIOSIS (Doctoral dissertation, Fakultas Kedokteran). 